Understanding Biology Using Peptides

Sylvie E. Blondelle (Editor)

American Peptide Society, 2005

\title{
Novel Blue- and Red-Shifted Internally Quenched Fluorogenic Substrates for Continuous Monitoring of SARS-CoV $3 C^{\text {pro }}$
}

\author{
Pamela Hamill ${ }^{1}$, Martin Richer ${ }^{1}$, Derek Hudson ${ }^{2}$, Hongyan $\mathrm{Xu}^{3}$ and \\ François Jean ${ }^{1}$ \\ ${ }^{I}$ Department of Microbiology and Immunology, University of British Columbia, Vancouver, \\ BC, V6T 1Z3, Canada; ${ }^{2}$ Biosearch Technologies Inc., Novato, CA, 94949-5750, USA; \\ ${ }^{3}$ GL Biochem Ltd., Shanghai, 201203, China
}

\section{Introduction}

The SARS coronavirus (SARS-CoV)-encoded main protease, $3 \mathrm{CL}^{\text {pro }}$ or $\mathrm{M}^{\text {pro }}$, plays an essential role in the viral life cycle and is currently the main focus for the development of anti-coronaviral therapies. The genome of SARS-CoV is translated in the cytoplasm of infected cells to generate several large polyproteins. For viral replication to occur, these polyproteins must be proteolytically processed into individual proteins, a process that is mediated by two viral proteases; PL2 $2^{\text {pro }}$ and $3 \mathrm{CL}^{\text {pro }}[1]$. $3 \mathrm{CL}^{\text {pro }}$ is considered the main viral protease as it releases the key replicative proteins of the virus, including the viral RNA polymerase and helicase proteins. Since the emergence of SARS-CoV in late 2002, the development of sensitive assays to detect recombinant $3 \mathrm{CL}^{\text {pro }}$ activity in formats amenable to highthroughput screening (HTS) has been a priority for the generation of novel $3 \mathrm{CL}^{\text {pro }}$ inhibitors as anti-viral therapies. Here, we report our success in developing blueand red-shifted internally quenched fluorogenic substrates (IQFSs) based on resonance energy transfer between the donor and acceptor pairs $\mathrm{Abz} / \mathrm{Tyr}\left(3-\mathrm{NO}_{2}\right)$ [IQFS-1], and CAL Fluor Red 610 (CalRed 610)/Black Hole Quencher-2 (BHQ-2) [IQFS-2], using a decapeptide sequence corresponding to that of the cleavage site between the non-structural protein (nsp)4/nsp5 in the SARS-CoV polyprotein pp1ab.

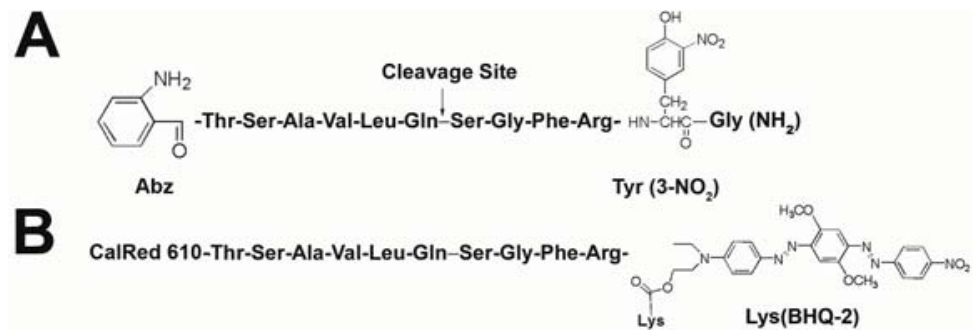

Fig. 1. Amino acid sequences of SARS-CoV 3CL pro IQFSS (A) IQFS-1 and (B) IQFS-2. The chemical structures of the donor group o-aminobenzoyl (Abz) and acceptor groups 3nitrotyrosine (3-NO $\mathrm{N}_{2}$ [2-4] and Black Hole Quencher-2 (BHQ-2) are shown.

\section{Results and Discussion}

SARS-CoV 3 CL $^{\text {pro }}$ quenched fluorescent substrate IQFS-1 (Fig. 1) was synthesized using Fmoc solid phase peptide chemistry [2-4]. The synthesis protocol for IQFS-2 will be presented elsewhere (Hamill P. et al., manuscript in preparation). In both cases, peptide purity and composition were demonstrated by RP-HPLC, mass spectrometry and amino acid analysis. Following expression in E. coli, His-tagged SARS-CoV $3 \mathrm{CL}^{\mathrm{pro}}$ was purified to $>90 \%$ homogeneity by nickel chromatography. 
The ability of purified SARS-CoV $3 \mathrm{CL}^{\text {pro }}$ to cleave both IQFSs was then tested by using a continuous protease assay (Fig. 2A) and RP-HPLC assay (Fig. 2B and 2C).
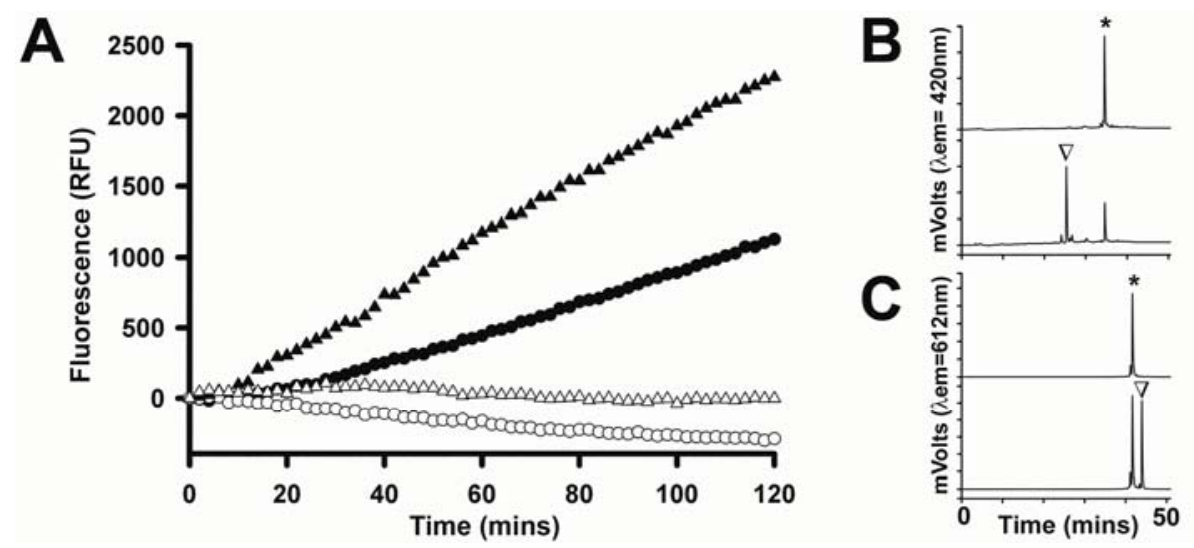

Fig. 2. Processing of blue- and red-shifted quenched fluorescent peptidyl substrates by recombinant SARS-CoV $3 C L^{\text {pro }}$ (A) Continuous protease assay using a fluorescence plate reader [3-4]. IQFS-1 and IQFS-2 were added at concentrations of $36 \mu \mathrm{M}$ or $18 \mu \mathrm{M}$, respectively, to assay reactions containing $500 \mathrm{nM}$ of $3 \mathrm{CL}^{\text {pro }}$ in reaction buffer $(50 \mathrm{mM}$ Hepes, $100 \mathrm{mM} \mathrm{NaCl},[\mathrm{pH} 7.3], 10 \mathrm{mM}$ DTT and $10 \mu \mathrm{g} /$ well of BSA) at $30^{\circ} \mathrm{C}$. The fluorescence emitted from reactions in the presence (closed symbols) or absence (open symbols) of $3 C^{\text {pro }}$

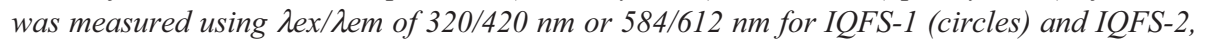
(triangles) respectively. RP-HPLC analysis [4] of fluorescent peptide products present in reactions containing (B) IQFS- 1 and (C) IQFS-2 in the absence (top panel) or presence (lower panel) of $3 C^{\text {pro. Intact IQFS }}\left(^{*}\right)$ and $N$-terminal cleavage products $(\nabla)$ are indicated.

Our results show that both the blue- and red-shifted IQFSs are sensitive substrates that are efficiently processed at low micromolar concentration by recombinant SARS-CoV $3 \mathrm{CL}^{\text {pro }}$ in our continuous assay. In addition, we demonstrate that both are cleaved in one position only following the glutamine residue, consistent with the known proteolytic specificity of SARS-CoV $3 \mathrm{CL}^{\text {pro }}$. Our novel in vitro continuous assay system utilizing both blue- and red-shifted IQFS is advantageous since both the efficacy and mode of inhibition of putative $3 \mathrm{CL}^{\text {pro }}$ inhibitors can be determined. Moreover, our dual-substrate continuous $3 \mathrm{CL}^{\text {pro }}$ assay may offer advantages for HTS of small molecule natural-colored compounds, since the number of false positives resulting from non-specific interference with the fluorophore group may be reduced.

\section{Acknowledgments}

Supported by NCE/PENCE and CIHR (F. Jean). F. Jean is a CIHR Scholar.

\section{References}

1. Ziebuhr, J. Curr. Opin. In. Micro. 7, 412-19 (2004).

2. Jean, F., Basak, A., DiMaio, J., Seidah, N. G. and Lazure, C. Biochem. J. 307, 689-695 (1995).

3. Richer, M., Juliano, L., Hashimoto, C. and Jean, F. J. Biol. Chem. 279, 10222-10227 (2004).

4. Hamill, P. and Jean, F. Biochemistry 44, 6586-6596 (2005). 